\title{
Typologies of young pathological gamblers based on sociodemographic and clinical characteristics
}

\author{
Susana Jiménez-Murcia ${ }_{\lambda}^{\mathrm{a}, \mathrm{b}, \mathrm{c}, *}, \mathrm{R}_{\Lambda}$ oser Granero ${ }_{\lambda}^{\mathrm{b}, \mathrm{d}}$, Randy Stinchfield $\mathrm{R}_{\lambda}^{\mathrm{e}}$, \\ Fernando Fernández-Aranda $\lambda_{\wedge}^{a, b, c}$, Eva Penelo ${ }_{\lambda}^{d}$, Lamprini G. Savvidou ${ }_{\wedge}^{a}$, Frida Fröberg ${ }_{\lambda}^{f}$, \\ Neus Aymamía ${ }_{\wedge}^{\mathrm{a}}$, Mónica Gómez-Peña ${ }_{\wedge}^{\mathrm{a}}$, Laura Moragas ${ }_{\wedge}^{\mathrm{a}}$, Amparo del Pino-Gutiérrez ${ }_{\wedge}^{\mathrm{a}, \mathrm{g}}$, \\ Ana B. Fagundo $o_{\wedge}^{a, b}$, José M. Menchón $n_{\wedge}^{\mathrm{a}, \mathrm{c}, \mathrm{h}}$ \\ ${ }^{a}$ Department of Psychiatry, Pathological Gambling Unit, Bellvitge University Hospital-IDIBELL, Barcelona, Spain \\ ${ }^{\mathrm{b}}$ Ciber Fisiopatología Obesidad y Nutrición (CIBERObn), Instituto de Salud Carlos III, Spain \\ ${ }^{\mathrm{c}}$ Department of Clinical Sciences, School of Medicine, University of Barcelona, Spain \\ ${ }^{\mathrm{d} D e p a r t a m e n t ~ d e ~ P s i c o b i o l o g i a ~ i ~ M e t o d o l o g i a ~ d e ~ l e s ~ C i e ̀ n c i e s ~ d e ~ l a ~ S a l u t, ~ U n i v e r s i t a t ~ A u t o ̀ n o m a ~ d e ~ B a r c e l o n a, ~ S p a i n ~}$ \\ ${ }^{\mathrm{e}}$ Department of Psychiatry, University of Minnesota Medical School, USA \\ ${ }^{\mathrm{f}}$ Department of Clinical Neuroscience, Karolinska Institutet, Sweden \\ ${ }^{\mathrm{g}}$ Departament d'Infermeria de Salut Pública, Salut Mental i Maternoinfantil, Escola Universitària d'Infermeria, Universitat de Barcelona, Spain \\ ${ }^{\mathrm{h}}$ CIBER Salud Mental (CIBERSAM), Instituto de Salud Carlos III, Spain
}

\section{Abstract}

Objective: The aim of this study is to explore empirical clusters within the population of young Spanish individuals attending outpatient pathological gambling treatment.

Method: The South Oaks Gambling Screen (SOGS), the Symptom Checklist (SCL-90-R), the Temperament and Character Inventory-R (TCI-R) and other clinical and psychopathological measures were administered to 154 patients (between 17 and 25 years old). The two-step cluster analysis explored the presence of empirical heterogeneous groups based on clinical and socio-demographic characteristics.

Results: Three clusters of young pathological gambling patients emerged. Type I showed less psychopathology and more functional personality traits. Type II showed a profile characterized by major emotional distress, shame, immaturity, hostility and negative feelings. Type III showed the most severe psychopathological profile and most psychopathological disturbances and schizotypal traits.

Conclusions: These results suggest that three distinct endophenotypes exist, and that environmental factors have a stronger influence in the first, while in the second and third, individual factors related to deficits of emotional regulation stand out.

(C) 2013 Published by Elsevier Inc.

\section{Introduction}

Pathological gambling (PG) is defined by uncontrollable gambling behavior that results in severe negative effects on the patient's occupation, relationships, psychological health and other relevant areas of life [1]. Moreover, although people suffering from this disorder recognize that gambling is the reason of severe impairments in the family and on a

* Corresponding author. Department of Psychiatry, Bellvitge University Hospital-IDIBELL and CIBERObn. c/ Feixa Llarga s/n, 08907L'Hospitalet de Llobregat, Barcelona, Spain. Tel.: +34 9326079 88; fax: +34 9326076 58 .

E-mail address: sjimenez@bellvitgehospital.cat (S. Jiménez-Murcia). community level (many patients indicate that gambling was 35 the reason they lost significant relationships and jobs), they 36 cannot resist the impulse to gamble.

According to Chiu \& Storm [2], youth are overly sensitive 38 to norms that contribute to the maintenance of high-risk 39 behaviors such as gambling. Further studies consistently 40 report that youth problem gambling is associated with other 41 psychosocial problems, such as depression, substance abuse, 42 and delinquency $[3,4]$. The first exposure to gambling 43 usually happens early in life, in the form of electronic and/or 44 internet gambling, lotteries, slot-machines, card games, 45 casinos, and many other types of games [5]. This early 46 exposure represents one of the critical risk factors for the 47 onset of PG. Furthermore, the main steps or actions that form 48 
t1.14 Number of problematic games; mean (SD)

t1.15 Evolution (years); mean (SD)

t1.16 Age of onset; mean (SD)

t1.17 Maximum bets (euros); mean (SD)

t1.18 Mean bets (euros); mean (SD)

t1.19 Cumulate debts (euros); mean (SD)

Table 1

Socio demographic and socio-economic characteristics

Age (years); mean (SD) the addictive behavior are located in the same social atmosphere, involving gambling as well as the excitement of risk-taking (strong characteristic of youth).

It is crucial to identify PG behaviors while still in their earliest manifestations, since the persistence to gamble involves the accumulation of negative social and psychopathological consequences, such as unemployment, debts, disrupted family relationships, and search for money by illegal means, substance abuse and affective-anxiety isorders [6].

Even though there is strong evidence about the heterogeneity of PG and the existence of different subgroups based on socio demographic and clinical characteristics among adults [7-11], few studies have attempted to identify clusters of young pathological gamblers. An exception is the recent work published by Gupta et al. [12], which was conducted with students of English-speaking schools in Quebec and Ontario. This study explores the "Pathways Model" proposed by Blaszczynski \& Nower [8], in a sample of 109 adolescents that meet the criteria for problem gambling. The results suggest that, in addition to the three subtypes described in the "Pathways Model" (behaviorally conditioned, emotionally vulnerable and antisocial impulsive problem gamblers) there are two more subtypes, one characterized by depressive symptoms and the other by externalizing and internalizing symptoms. Furthermore, Goldstein et al. [13] examined subgroups of gamblers among adolescent emergency patients, finding two groups with few or many consequences of gambling. The group with many consequences also exhibited substance abuse, delinquency and violence, and resembled Pathway 3 in the model by Blaszczynski \& Nower [8].

The aim of this study is to explore empirical clusters in a sample of Spanish young people (17-25 years old) attending outpatient PG treatment. Based on empirical evidence, we hypothesized that it would be possible to identify clinically 84 relevant subgroups of young PG patients, based on 85 psychopathology and personality traits. We expected to 86 identify one subgroup characterized by low psychopathol- 87 ogy and non-dysfunctional personality traits, a second with 88 moderate psychopathology and melancholic personality 89 traits (following character types described by Cloninger et 90 al. [14] and a third formed by a subgroup of patients with 91 severe psychopathology and disorganized or schizotypal 92 personality configuration (as defined by Cloninger et al. [14]. 93

\section{Method}

\subsection{Participants}

The sample included 154 pathological gambling patients, 96 17-25 years old, who presented for assessment and 97 outpatient treatment at the Pathological Gambling Unit in 98 the Psychiatric Department of Bellvitge University Hospital 99 (HUB) in Barcelona. All participants were diagnosed by 100 experienced psychologists and psychiatrists in PG, using the 101 Diagnostic Questionnaire for Pathological Gambling accord- 102 ing to DSM-IV criteria [15].

The first column of Table 1 shows the socio demographic 104 and clinical characteristics of the sample. The mean age was 105 22.4 years old $(S D=2.2), 94.2 \%$ were male and $61.3 \%$ of 106 them were employed at the intake. More than half of the 107 sample had achieved no more than primary educational level 108 and only $\mathbf{1 1 . 3 \%}$ were married or lived with a partner. $\quad 109$

\subsection{Measures}

110

South Oaks Gambling Screen (SOGS) [16], Spanish 111 validation by Echeburúa et al. [17]. This is a 20-item 112 screening questionnaire that identifies probable pathological 113 gambling. The Spanish validation of this questionnaire 114

Differences between clusters regarding socio demographic and socio-economic characteristics and clinical measures.

Employment status (employed); \%

Educational level; \% Primary or less

Civil status; \% Without partner

incomes (euros); mean (SD)

p-value including Bonferroni-Finner's correction. SD: standard deviation.
$22.4(2.2)$

\section{2}

61.3

56.4

$89.0 \%$

704 (603)

75.2

$1.5(0.8)$

$2.8(2.5)$

$20.0(2.6)$

$741(1107)$

86 (143)

2842 (5723)
2482 (1560)

$\begin{array}{llll}\begin{array}{l}\text { Total sample } \\ (n=154)\end{array} & \begin{array}{l}\text { Cluster } 1 \\ (n=52)\end{array} & \begin{array}{l}\text { Cluster } 2 \\ (n=44)\end{array} & \begin{array}{l}\text { Cluster } 3 \\ (n=14)\end{array}\end{array}$

$22.6(2.1)$
100
73.1
48.1
94.2
$907(579)$
$2613(1664)$
74.4

$23.0(2.3)$
93.2
63.6
72.7
86.0
$751(524)$
$2322(1643)$
86.5

$1.33(0.57)$

2.55 (2.04)

20.42 (2.12)

688 (1394)

80 (110)

3144 (6931) 2635 (5157)

$\begin{array}{cc}22.6(1.8) & .692 \\ 100 & .374 \\ 57.1 & .625 \\ 78.6 & .252 \\ 78.6 & .478 \\ 771(841) & .625 \\ 3067(1679) & .625 \\ 69.2 & .597 \\ & \\ 2.00(1.15) & .252 \\ 2.54(2.23) & .597 \\ 20.31(2.27) & .625 \\ 1454(1148) & .374 \\ 131(286) & .646 \\ 2620(2721) & .942\end{array}$

692

374

625
252

478

625 625 52

8


shows high reliability and validity. Test-retest reliability is $.98(\mathrm{p}<0.001)$ and internal consistency .94 (Cronbach's alpha). Convergent validity with respect to DSM-III-R criteria for pathological gambling (APA, 1987) was estimated $.92(p<0.001)$. The total score was used in this study. Additionally, several studies have reported the use and utility of this test as an index of gambling severity [18-20].

Diagnostic questionnaire for Pathological Gambling according to DSM-IV criteria [15]. Spanish adaptation by Jimenez-Murcia et al. [21]. This 19-item questionnaire assesses the DSM-IV diagnostic criteria for PG. Internal consistency ranged between .81 for the general population and .77 for gambling treatment samples. Convergent validity with the SOGS total score was very good: $r=.77$ for the general population and $r=.75$ for gambling treatment groups [15].

Symptom Check List-90 items-Revised (SCL-90-R, Spanish version) [22]. We administered the SCL-90-R to evaluate a broad range of psychological problems and symptoms of psychopathology. Containing 90 items, the SCL-90-R is used to measure nine primary symptom dimensions: Somatization, Obsession-Compulsion, Interpersonal Sensitivity, Depression, Anxiety, Hostility, Phobic Anxiety, Paranoid Ideation, and Psychoticism. In addition, it includes three global indices: a global severity index (GSI), which measures overall psychological distress; a positive symptom distress index (PSDI) to measure the intensity of symptoms; and a positive symptom total (PST), which reports the total self-reported symptoms. The GSI can be used as a summary of the test. This scale has been validated in a Spanish population, obtaining an internal consistency (coefficient alpha) of the items ranging between .81 and .90 .

Temperament and Character Inventory-Revised (TCI-R) [23]. This is a 240 -item questionnaire. Like the original TCI version [14], this questionnaire is a reliable and valid measure of seven dimensions of personality: four temperament dimensions (harm avoidance, novelty seeking, reward dependence and persistence) and three character dimensions (self-directedness, cooperativeness and self-transcendence). The performance of the Spanish revised version of this questionnaire [24] has been well-documented. The reliability of the different temperament and character dimensions in the Spanish adaptation ranged between .77 and .84 (Cronbach's alpha)

Additional demographic, clinical and socio-familial variables related to gambling were measured using a semistructured clinical interview, described elsewhere $[25,26]$.

\subsection{Procedure}

This study was carried out according to the latest version of the Declaration of Helsinki. The Ethics Committee of the Bellvitge University Hospital (Barcelona) approved this study and written informed consent was obtained from all final participants.
The assessment was conducted prospectively at base- 169 line and it involved a single session (with a mean 170 duration of $90 \mathrm{~min}$ ), during which the above mentioned 171 tests were administered by trained clinical psychologists. 172 In addition to the assessment battery, the patients were 173 explored through a semi-structured face-to-face interview 174 regarding their PG, psychopathological symptoms and 175 personality traits (Jiménez-Murcia et al., 2007). The same 176 interview also assessed sociodemographic data (e.g., 177 education, occupation, marital status) and additional 178 clinical information.

\subsection{Statistical analysis}

A two-step cluster analysis explored the presence of 181 empirical groups based on the socio demographic and 182 clinical variables (number of problematic games, co- 183 morbidity, SCL-90-R and TCI-R scores, SOGS and DSM 184 Total scores). The two-step method allows discriminating 185 natural groups from a set of variables stabilizing the nearness 186 criterion, with a hierarchical agglomerative clustering whose 187 centres are far apart. Likelihood was the distance measure 188 selected, defining the normal density for continuous vari- 189 ables and the multinomial probability mass function for 190 categorical variables [27]. Average Silhouette Coefficient (a 191 measure of how tightly grouped all the data in the cluster are) 192 measured the goodness-of-fit [28]. This index combines 193 both, cohesion (based on the average distances between all 194 the objects into a cluster) and separation (based on the 195 average distance of any object to all the other objects not 196 contained into the same cluster), and can range between -1197 and +1 ; values over 0 are indicative of inappropriate fit, 198 between 0 and 0.2 are considered poor, between 0.2 and 0.5199 fair and indices above 0.5 good.

Next, binary logistic regressions (for categorical criteria) 201 and analysis of variance (ANOVA, for quantitative out- 202 comes) compared the empirical clusters on all the measures 203 of the study. Cohen's $d$ measured the effect size of 204 proportions and mean differences $(d$-coefficients over 0.50205 were considered good). Due to the multiple statistical 206 comparisons, Bonferroni-Finner's correction was applied 207 to avoid bias due to Type-I error.

\section{Results}

Cluster analysis was carried out with 110 participants 210 (71.4\% of sample), who had completed all the measures of 211 the study and were considered valid for the analysis. There 212 were no statistical differences between those included (with 213 complete information) and excluded (due to missing data) 214 into the two-step cluster analysis in the set of variables 215 available. Three clusters emerged, with sample sizes of 52216 (47.3\%), $44(40.0 \%)$ and $14(12.7 \%)$ (the ratio of sizes 217 comparing the largest to smallest cluster was 3.71). 218 Goodness-of-fit was achieved, with fair average Silhouette 219 Coefficient equal to 0.30 . 
t2.15 2-Amount money spent: $\geq 300$ euros

t2.16 3-Family antecedents of gambling

t2.17 4-Going back to win back lost money

t2.18 5-Claimed winning when loosing

t2.19 6-Problem recognition

t2.20 7-Gambling more than planned

t2.21 8-Being criticized

t2.22 9-Feeling guilty

t2.23 10-Unable to stop gambling

t2.24 11-Hiding signs of gambling

t2.25 12-Discussions with family/friends

t2.26 13-Discussions and fights

t2.27 14-Borrowing money, not paying back

t2.28 15-Skipping work due to gambling

t2.29 16a-Money from home

t2.30 16b-Money from couple

t2.31 16c-Money from family

t2.32 16d-Money from banks

t2.33 16e-Credit cards

t2.34 16f-Money from money lender

t2.35 $16 \mathrm{~g}$-Money from financial papers

t2.36 16 h-Money from property sales

t2.37 16i-Money from falsified checks

t2.38 16j-Money from credit account casino

t2.39 SOGS: total score; mean (SD)

t2.40 DSM-IV: total criteria; mean (SD) mographic composition of skipping school or work due to gambling, obtaining money 237 from family or banks, using credit cards for gambling and 238 obtaining money for gambling from property sales $(1.7 \%$ vs. 239 $20.8 \%$ ).

Table 3 shows the comparison of general psychopathol- 241 ogy (SCL-90-R) and personality traits (TCI-R) mean scores 242 between clusters. ANOVA tests obtained significant mean 243 differences between clusters for all the scales, except for 244 TCI-R novelty seeking, reward dependence and persistence. 245 Post-hoc comparisons showed that the three clusters differed 246 in all the measures (except for the TCI-R novelty seeking, 247 reward dependence and persistence scales), with the highest 248 mean scores for patients in cluster 3 followed by cluster 2. 249 Effect sizes were good to very good (Cohen's $d$ clearly over 250 0.50), except for the three TCI-R scores that did not achieve 251 statistical significant differences.

t2.41 $p$-value with Bonferroni-Finner's correction. SD: standard deviation, - : not estimable due extreme prevalences.

t2.42 a OR/MD: odds ratio and mean differences, respectively.

t2.43 * Bold: significant contrast (.05) or good Cohen's $d$. 
Table 3

Differences between clusters on psychopathology and personality measures.

\begin{tabular}{|c|c|c|c|c|c|c|c|c|c|c|c|c|c|}
\hline & \multicolumn{6}{|c|}{ Mean; standard deviation } & \multicolumn{7}{|c|}{ Comparison between clusters: contrasts (Cohen's d) } \\
\hline & \multicolumn{2}{|l|}{$\begin{array}{l}\text { Cluster } 1 \\
(n=52)\end{array}$} & \multicolumn{2}{|l|}{$\begin{array}{l}\text { Cluster } 2 \\
(n=44)\end{array}$} & \multicolumn{2}{|l|}{$\begin{array}{l}\text { Cluster } 3 \\
(n=14)\end{array}$} & $p$ & \multicolumn{2}{|l|}{$\mathrm{Cl} 1$ vs $\mathrm{Cl} 2$} & \multicolumn{2}{|l|}{$\mathrm{Cl} 1$ vs $\mathrm{Cl} 3$} & \multicolumn{2}{|c|}{$\mathrm{Cl} 2$ vs $\mathrm{Cl} 3$} \\
\hline \multicolumn{14}{|l|}{ SCL-90-R scores } \\
\hline Somatization & 0.34 & 0.36 & 0.95 & 0.51 & 2.18 & 0.87 & $<.001$ & $-0.61 *$ & $(1.38)$ & $-1.84 *$ & $(2.76)$ & $-1.23 *$ & $(1.72)$ \\
\hline Obsessive/compulsive & 0.52 & 0.38 & 1.23; & 0.50 & 2.43; & 0.69 & $<.001$ & $-0.71 *$ & $(1.60)$ & $-1.91 *$ & $(3.43)$ & $-1.20 *$ & (1.99) \\
\hline Interpersonal sensitivity & 0.30 & 0.28 & 1.10 & 0.52 & 2.19 & 0.87 & $<.001$ & $-0.80 *$ & $(1.92)$ & $-1.89 *$ & $(2.92)$ & $-1.09 *$ & $(1.52)$ \\
\hline Depressive & 0.58 & 0.44 & 1.59 & 0.58 & 2.45 & 0.71 & $<.001$ & $-1.01 *$ & $(1.96)$ & $-1.87 *$ & $(3.17)$ & $-0.86 *$ & $(1.33)$ \\
\hline Anxiety & 0.36 & 0.36 & 1.13 & 0.54 & 2.43 & 0.54 & $<.001$ & $-0.78 *$ & $(1.68)$ & $-2.07 *$ & $(4.51)$ & $-1.29 *$ & $(2.41)$ \\
\hline Hostility & 0.44 & 0.36 & 1.22 & 0.71 & 2.38 & 1.03 & $<.001$ & $-0.79 *$ & (1.39) & $-1.95 *$ & $(2.51)$ & $-1.16 *$ & (1.31) \\
\hline Phobic anxiety & 0.15 & 0.22 & 0.46 & 0.49 & 1.56 & 0.92 & $<.001$ & $-0.31 *$ & $(0.82)$ & $-1.41 *$ & (2.11) & $-1.10 *$ & (1.49) \\
\hline Paranoid Ideation & 0.34 & 0.34 & 1.02 & 0.59 & 2.06 & 0.67 & $<.001$ & $-0.68 *$ & (1.41) & $-1.72 *$ & (3.24) & $-1.04 *$ & (1.65) \\
\hline Psychotic & 0.27 & 0.31 & 0.96 & 0.43 & 1.98; & 0.47 & $<.001$ & $-0.69 *$ & $(1.84)$ & $-1.71 *$ & $(4.30)$ & $-1.02 *$ & (2.26) \\
\hline GSI score & 0.40 & 0.24 & 1.13 & 0.32 & 2.22 & 0.43 & $<.001$ & $-0.73 *$ & $(2.58)$ & $-1.82 *$ & $(5.23)$ & $-1.09 *$ & $(2.88)$ \\
\hline PST score & 24.6 & 13.8 & 53.5 & 12.5 & 71.6; & 8.55 & $<.001$ & $-28.9 *$ & (2.19) & $-47.0 *$ & $(4.09)$ & $-18.03 *$ & (1.69) \\
\hline PSDI score & 1.41 & .29 & 1.90 & 0.31 & 2.80 & 0.46 & $<.001$ & $-0.49 *$ & (1.63) & $-1.39 *$ & (3.61) & $-0.90 *$ & (2.29) \\
\hline \multicolumn{14}{|l|}{ TCI-R scores } \\
\hline Novelty seeking & 112.2 & 13.1 & 115.0; & 11.7 & 117.0; & 13.1 & .362 & -2.78 & $(0.22)$ & -4.81 & $(0.37)$ & -2.02 & $(0.16)$ \\
\hline Harm avoidance & 92.4 & 13.8 & 101.6; & 16.1 & 106.3; & 7.0 & .001 & $-9.15 *$ & $(0.61)$ & $-13.8 *$ & $(1.27)$ & -4.69 & $(0.38)$ \\
\hline Reward dependence & 100.7 & 15.7 & 94.5 & 15.2 & 99.6 & 9.8 & .137 & 6.75 & $(0.40)$ & 1.07 & $(0.08)$ & -5.10 & $(0.40)$ \\
\hline Persistence & 110.4 & 19.2 & 108.6; & 22.8 & 113.3; & 15.8 & .749 & 1.75 & $(0.08)$ & -2.90 & $(0.16)$ & -4.65 & $(0.24)$ \\
\hline Self-directedness & 139.1; & 18.0 & 119.5; & 16.0 & 107.4; & 14.4 & $<.001$ & $19.6 *$ & $(1.15)$ & $31.7 *$ & $(1.94)$ & $12.12 *$ & $(0.79)$ \\
\hline Cooperativeness & 132.2 & 18.9 & 124.4 & 17.5 & 111.9; & 16.1 & .001 & 7.79 & $(0.43)$ & $20.3 *$ & $(1.16)$ & $12.5 *$ & $(0.74)$ \\
\hline Self-Transcendence & 55.7 & 14.1 & 65.5 & 14.2 & 75.4 & 11.7 & $<.001$ & $-9.74 *$ & $(0.69)$ & $-19.7 *$ & $(1.52)$ & $-9.90 *$ & $(0.76)$ \\
\hline
\end{tabular}

p-value including Bonferroni-Finner's correction.

* Bold: significant contrast (mean differences with Scheffé procedure).

\section{Discussion}

The heterogeneity of PG has led to several attempts to establish different subtypes within the spectrum of the disorder. This study found evidence for three different clusters of young people, aged 17 to 25 years attending outpatient PG treatment.

The sociodemographic features were equally distributed between clusters, with the exception of educational level. Lack of education was associated with greater PG severity. The first cluster (or Type I) was composed of cases with high educational level (secondary or university studies) and who reported fewer negative consequences of gambling according to the questions in the SOGS (spending more money gambling, returning to win back lost money, gambling more than planned, being criticized due to the gambling addiction, being unable to stop gambling, borrowing money and not paying back, skipping school or work due to gambling, using credit cards to gamble and obtaining money destined to gambling from property sales). This cluster also achieved the lowest mean scores in the severity of the disorder (SOGSTotal score and DSM-IV-Total score), lower levels of general psychopathology (assessed with the SCL-90-R questionnaire) and healthier personality traits (lower scores on Harm Avoidance and Self-Transcendence and higher on Self-Directedness and Cooperativeness). This subtype, which we named High General Functioning (Type I), coincides with the "Behaviorally Conditioned Problem Gamblers" Pathway 1 type among adult PGs, as described by Blaszczynski \& Nower [8]. Our High General Function-

ing group (Type I) was the healthiest group compared to the 282 other two in terms of psychopathology. If anxiety or 283 depressive symptoms were present among these patients, 284 they would be treated quickly once treatment is initiated. 285 Type I also coincides with cluster I described in a study by 286 Lesieur [29] named "normal problem gambler": a group that 287 presented low levels of psychopathology, impulsivity, 288 depression, and anxiety, amongst other clinical characteris- 289 tics. Likewise, our Type I resembles Class 2 in the study by 290 Gupta et al. [12] conducted among adolescents.

The second cluster (Type II) that we call Depressive Type 292 was characterized by major emotional distress, shame, 293 immaturity, hostility and negative feelings. This cluster 294 resembles the Pathway 2 type among adults described by 295 Blaszczynski \& Nower [8] as "Emotionally Vulnerable 296 Problem Gamblers", and would include those PGs that have 297 suffered premorbid states of anxiety and depression, as well 298 as significant deficits in coping strategies. This type feels the 299 need to regulate and modulate their negative emotional states 300 through gambling behavior. Similarly, our group partially 301 coincides with the cluster II identified by Lesieur [29], which 302 he labeled as "moderately-impulsive action seeker" patients 303 with moderate levels of psychopathology and impulsivity, as 304 well as those with more severe gambling behavior. However, 305 Lesieur's cluster also includes individuals with early age of 306 onset and high levels of search for excitement.

Our Type II coincides with those called Class 4 and 5 in 308 the study of Gupta et al. [12] among adolescents. While 309 Class 4 is associated with depression, suicidal tendencies, 310 childhood abuse and family conflicts, Class 5 is strictly 311 
associated with depressive symptoms (which the authors suggest as a unique subtype in adolescents). According to the Cloninger et al. [14] model of personality, three character dimensions (Self-directedness, Cooperativeness and SelfTranscendence) can be subsyndromic indicators of depressive or psychotic episodes. In our Type II, we observe low scores in Self-Directedness and Cooperativeness, but moderate scores in Self-Transcendence. This profile would fit the melancholy character, described by Cloninger et al. [14], in which immature traits, emotional reactivity, selfishness, competition and rivalry feelings toward others are present. Basically, the affective state of these individuals would be negative, rarely experiencing positive emotions. In these cases, and as suggested by Blaszczynski \& Nower [8], gambling would be a maladaptive strategy to escape from and/or modulate these symptoms and negative emotions.

We identified a third subgroup, which we called Disorganized Type, or Type III, with the most severe psychopathological profile, including schizotypal traits, and most severe gambling behavior (assessed by the SOGS and DSM-IV questionnaires). Consistent with Cloninger et al. [14], these subjects, with low scores in Self-Directedness and Cooperativeness and high scores in Self-Transcendence, could be considered as disorganized or schizotypal. They would appear suspicious, illogical and immature, prone to imagination and fantasy, as well as demonstrating peculiar and unconventional behavior. In addition, this configuration is associated with the temperament traits Novelty Seeking and Harm Avoidance (as in the case of this subtype), as well as borderline personalities (explosive and overly-sensitive). This type coincides with the Pathway 3 among adults described by Blaszczynski \& Nower [8] as "Antisocial and Impulsivist Problem Gamblers": a subgroup with major alterations in psychopathology, major psychosocial interference due to their gambling behavior and more dysfunctional personality profiles. To these authors, this subgroup would represent an etiology of the disorder strongly associated with both neurobiological and psychological risk factors.

Both the subgroup described in the explanatory model of Blaszczynski \& Nower [8] and our Type III, are equivalent with the Class 1 in the study by Gupta et al. [12]. Furthermore, Goldstein et al. [13] found a subgroup of adolescent gamblers with many consequences of gambling that was associated with substance abuse, delinquency and violence, which resembles the "Antisocial Impulsivist"/ Pathway 3 in the model by Blaszczynski \& Nower [8] and our Type III which scored high on Novelty seeking. One may speculate that some of the adolescents in the high consequence group in the study by Goldstein et al. [13] represent our Type III at a younger age.

Lesieur's [29] cluster 3, composed of "impulsive escape seekers", only partially coincides with our results. In this group, Lesieur [29] included individuals with the most elevated levels of impulsivity and psychopathology, although also those with later age of onset and with low levels of excitement seeking. In other words, this group would better meet the Type II and Type III in our study and the 368 clusters 2 and 3 obtained by Blaszczynski and Nower [8]. 369 However, it is important to highlight that Lesieur's [29] 370 results were based on an inpatient sample, with elevated 371 levels of severity, which could explain the partial concor- 372 dance with the subtypes observed in other studies.

The impact that the identification of homogeneous 374 subgroups in PG has in the design of therapeutic approaches 375 is crucial. Although studies exploring the treatment response 376 suggest that this disorder can be successfully treated [30], 377 there are high rates of dropouts and relapses throughout the 378 rehabilitation process of these patients $[11,31]$. Studies about 379 the response to treatment programs show that mood 380 disorders or substance dependence [32] and dysfunctional 381 personality traits such as Sensation-seeking traits [33] Harm 382 Avoidance and Self-Directedness [34] are associated with 383 poor response to treatment. Based on research considering 384 the subgroups, including our present findings, we might 385 consider that the Type II and III patients would be those at 386 risk for a more torpid and complex response to treatment. 387 Therefore, including techniques and strategies for specific 388 treatment of cognitive strategies for inhibitory control or 389 regulation of negative emotions, among other aspects, could 390 be crucial to improve the results of treatment programs. It is 391 of great scientific interest to further investigate the 392 effectiveness of new tools aimed at treating the underlying 393 neurocognitive PG processes such as cognitive remediation 394 [35], serious games [36,37] or mindfulness training based 395 treatments [38].

\subsection{Limitations}

397

The first limitation concerns generalization: the results of 398 this study must only be extrapolated to populations of young 399 male gamblers who seek treatment due to problems related to 400 gambling. Another limitation is related to the sample size: 401 the small number of participants attenuated the power of the 402 cluster analysis to detect more differences for the set of 403 variables. Finally, although our main objective was to obtain 404 an early identification of the subtypes of pathological 405 gamblers, the average age of the sample was 22 years. The 406 facts that gambling is illegal under the age of 18 in our 407 country and that only the most severe cases seek treatment 408 [39] are factors that may be related to the average age of the 409 subjects studied. Several studies have shown that from the 410 start of gambling behavior to loss of control it usually takes 411 6-7 years $[5,40,41]$ which could also justify that although 412 gambling starts earlier for most people (in some cases 413 younger than 18), they do not seek treatment until they are 414 older (e.g. 20-22 years of age).

\subsection{Implications}

To our knowledge, this is the first study examining 417 subgroups of PG in a treatment-seeking sample of youth, so 418 the findings have high relevance from a clinical point of 419 view. 
Overall, the results of this work indicate that PG constitutes a complex disorder with heterogeneous clusters even among adolescents and young adults. Identifying the specific earliest manifestations of this problem is essential in order to develop adequate therapeutic programs and to prevent the disorder from progressing to the most severe stages. Finally, research should test for the empirical clusters that emerged in this study with larger and more diverse samples particularly in relation to gender and response to treatment. Future research on PG types should also consider examining biological, neuropsychological, biochemical and genetic variables. The goal is to better understand this disorder and provide more effective assessment and treatment.

\section{Acknowledgment}

Partial financial support was received from Ministerio de Economía y Copetitividad (PSI2011-28349) and AGAUR (2009SGR1554). CIBER Fisiopatología de la Obesidad y Nutrición (CIBERobn) and CIBER Salud Mental (CIBERsam), are both initiatives of ISCIII. This work is part of the $\mathrm{PhD}$ thesis of Lamprini G. Savvidou at the University of Barcelona (School of Medicine).

\section{References}

[1] American Psychiatric Association, APA. Diagnostic and statistical manual of mental disorders (4th ed. revised). Washington, DC: American Psychiatric Association; 2000.

[2] Chiu J, Storm L. Personality, perceived luck and gambling attitudes as predictors of gambling involvement. J Gambl Stud 2010;26:205-27.

[3] Blinn-Pike L, Worthy SL, Jonkman JN. Adolescent gambling. A review of an emerging field of research. J Adolesc Health 2010;47: 223-36.

[4] Hardoon KK, Gupta R, Derevensky JL. Psychosocial variables associated with adolescent gambling. Psychol Addict Behav 2004; 18:170-9.

[5] Jiménez-Murcia S, Álvarez-Moya E, Stinchfield R, Fernández-Aranda F, Granero R, Aymamí N, et al. Age of onset in pathological gambling: clinical, therapeutic and personality correlates. J Gambl Stud 2010;26(2):235-48, http://dx.doi.org/10.1007/s10899-009-9175-3.

[6] Raylu N, Oei TPS. Pathological gambling: a comprehensive review. Clin Psychol Rev 2002;22:1009-61.

[7] Álvarez-Moya E, Jimenez-Murcia S, Aymami MN, Gomez-Peña M, Granero R, Santamaria JJ, et al. Subtyping study of a male pathological gambling sample. Can J Psychiatry 2010;55(8):498-506.

[8] Blaszczynski A, Nower L. A pathways model of problem and pathological gambling. Addiction 2002;97(5):487-99.

[9] Cunningham-Williams RM, Hong SI. A latent class analysis (LCA) of problem gambling among a sample of community-recruited gamblers. J Nerv Ment Dis 2007;195:939-47.

[10] Gonzalez fbanez A, Aymami MN, Jimenez S, Domenech JM, Granere R, Lourido-Ferreira MR. Assessment of pathologieal gamblers who the slot machines. Psychol Rep 2003:93(3 Pt 1):707-16.

[11] Ledgerwood DM, Petry NM. Psychological experience of gambling and subtypes of pathological gamblers. Psychiatry Res 2006;144: 17-27.

[12] Gupta R, Nower L, Derevensky JL, Blaszczynski A, Faregh N, Temcheff C. Problem gambling in adolescents: an examination of the pathways model. J Gambl Stud 2012, http://dx.doi.org/10.1007/ 477 s10899-012-9322-0.

[13] Goldstein AB, Faulkner B, Cunningham RM, Zimmerman MA, 479 Chermack S, Walton MA. A latent class analysis of adolescent 480 gambling: application of resilience theory. Int J Ment Health Addiction 481 2013;11:13-30.

[14] Cloninger CR, Svrakic DM, Przybeck TR. A psychobiological model 483 of temperament and character. Arch Gen Psychiatry 1993;50(12): 484 975-90.

[15] Stinchfield R. Reliability, validity, and classification accuracy of a 486 measure of DSM-IV diagnostic criteria for pathological gambling. Am 487 J Psychiatry 2003;160:180-2.

[16] Lesieur HR, Blume SB. The South Oaks Gambling Screen (SOGS): a 489 new instrument for the identification of pathological gamblers. Am J 490 Psychiatry 1987;144(9):1184-8.

[17] Echeburúa E, Báez C, Fernández J, Páez D. Cuestionario de juego 492 patológico de South Oaks (SOGS): Validación española (South Oaks 493 Gambling Screen (SOGS): Spanish validation). Análisis de Modifica- 494 ción de Conducta 1994;20:769-91.

[18] Alessi SM, Petry NM. Pathological gambling severity is associated 496 with impulsivity in a delay discounting procedure. Behav Process 497 2003;64(3):345-54.

[19] Stinchfield R. Reliability, validity, and classification accuracy of the 499 South Oaks Gambling Screen (SOGS). Addict Behav 2002;27(1):1-19. 500

[20] Strong DR, Daughters SB, Lejuez CW, Breen RB. Using the Rasch 501 model to develop a revised Gambling Attitudes and Beliefs Scale 502 (GABS) for use with male college student gamblers. Subst Use Misuse 503 2004;39(6):1013-24.

[21] Jimenez-Murcia S, Stinchfield R, Alvarez-Moya E, Jaurrieta N, Bueno 505 B, Granero R, et al. Reliability, validity, and classification accuracy of 506 a Spanish translation of a measure of DSM-IV diagnostic criteria for 507 pathological gambling. J Gambl Stud 2009;25(1):93-104. 508

[22] Derogatis LR. SCL-90-R. Cuestionario de 90 síntomas. [SCL-90-R. 509 90-Symptoms Questionnaire]. Madrid: TEA; 1994.

[23] Cloninger CR. The Temperament and Character Inventory-Revised. 511 St. Louis, MO: Center for Psychobiology of Personality, Washington 512 University; 1999

[24] Gutierrez-Zotes JA, Bayon C, Montserrat C, Valero J, Labad A, 514 Cloninger CR, et al. Temperament and Character Inventory Revised 515 (TCI-R). Standardization and normative data in a general population 516 sample. Actas Esp Psiquiatr 2004;32(1):8-15. 517

[25] Jiménez-Murcia S, Bove FI, Vergé B, Álvarez-Moya E, Granero R, 518 Penelo E, et al. Cognitive-behavioral therapy for pathological 519 gambling in Parkinson's disease: a pilot controlled study. Eur Addict 520 Res 2012;18(6):265-74, http://dx.doi.org/10.1159/000337442. 521

[26] Jiménez-Murcia S, Aymamí MN, Gómez-Peña M, Álvarez-Moya EM, 522 Vallejo J. Protocols de tractament cognitivoconductual pel joc 523 patològic i d'altres addicions no tòxiques (Guidelines of cognitive- 524 behavioral treatment of pathological gambling and other non-toxic 525 addictions). Barcelona, Spain: Hospital Universitari de Bellvitge, 526 Departament de Salut, Generalitat de Catalunya; 2006.

[27] Fraley C, Raftery AE. How many clusters? Which clustering method? 528 Q4 Answers via model-based cluster analysis. $\mathrm{CJ}_{\Delta} 1998$;4:578-88. 529

[28] Rousseeuw PJ. Silhouettes: a graphical aid to the interpretation and 530 validation of cluster analysis. J Comput Appl Math 1998;20:53-65. 531

[29] Lesieur HR. Cluster analysis of types of inpatient pathological 532 gamblers. Dissertation Abstracts International: Section B: The 533 Sciences and Engineering 2001; 62: 4-B.

[30] Gooding P, Tarrier N. A systematic review and meta-analysis of 535 cognitive-behavioral interventions to reduce problem gambling: 536 hedging our bets? Behav Res Ther 2009;47(7):592-607. 537

[31] Melville KM, Casey LM, Kavanagh DJ. Psychological treatment 538 dropout among pathological gamblers. Clin Psychol Rev 2007;27(8): 539 944-58.

[32] Hodgins DC. el-Guebaly N. The influence of substance dependence 541 and mood disorders on outcome from pathological gambling: five-year 542 follow-up. J Gambl Stud 2010;26(1):117-27. 


\section{ARTICLE IN PRESS}

[37] Jiménez-Murcia S, Fernández-Aranda F, Kalapanidas E, Konstantas D, 558 Ganchev T, Kocsis O, et al. Playmancer project: a serious videogame 559 as an additional therapy tool for eating and impulse control disorders. 560 Stud Health Technol Inform 2009;144:163-6.

[38] Witkiewitz K, Lustyk MK, Bowen S. Retraining the addicted brain: a 562 Q5 review of hypothesized neurobiological mechanisms of mindfulness- 563 based relapse prevention. Psychol Addict Behav 2012.

[39] Slutske WS. Natural recovery and treatment-seeking in pathological 565 gambling: results of two U.S. national surveys. Am J Psychiatry 566 2006;163(2):297-302.

[40] Breen RB, Zimmerman M. Rapid onset of pathological gambling in 568 machine gamblers. J Gambl Stud 2002;18(1):31-43. Soto A, Kalapanidas E, et al. Video games as a complementary therapy tool in mental disorders: Playmancer, a European multicentre study. J Ment Health 2012;21(4):364-74. gambling progression. J Gambl Stud 2001;17(2):151-9. 571
[41] Tavares H, Zilberman ML, Beites FJ, Gentil V. Gender differences in 570 


\section{AUTHOR QUERY FORM}

\begin{tabular}{|c|c|c|}
\hline ELSEVIER & $\begin{array}{l}\text { Journal: YCOMP } \\
\text { Article Number: } \mathbf{5 1 1 0 0}\end{array}$ & $\begin{array}{l}\text { Please e-mail or fax your responses and any corrections to: } \\
\text { Elsevier } \\
\text { E-mail: corrections.esi@elsevier.spitech.com } \\
\text { Fax: }+16196996721\end{array}$ \\
\hline
\end{tabular}

Dear Author,

Please check your proof carefully and mark all corrections at the appropriate place in the proof (e.g., by using on-screen annotation in the PDF file) or compile them in a separate list. Note: if you opt to annotate the file with software other than Adobe Reader then please also highlight the appropriate place in the PDF file. To ensure fast publication of your paper please return your corrections within 48 hours.

For correction or revision of any artwork, please consult http://www.elsevier.com/artworkinstructions.

Any queries or remarks that have arisen during the processing of your manuscript are listed below and highlighted by flags in the proof. Click on the 'Q' link to go to the location in the proof.

\begin{tabular}{|l|l|}
\hline $\begin{array}{c}\text { Location } \\
\text { in article }\end{array}$ & \multicolumn{1}{c|}{$\begin{array}{c}\text { Query / Remark: click on the Q link to go } \\
\text { Please insert your reply or correction at the corresponding line in the proof }\end{array}$} \\
\hline Q1 & Please confirm that given names and surnames have been identified correctly. \\
\hline Q2 & There were no table entries in bold. Please check. \\
\hline Q3 & Please provide page range here. \\
\hline Q4 & Please provide the journal name. \\
& $\begin{array}{l}\text { Please provide page range here. } \\
\text { Please check this box if you have no } \\
\text { corrections to make to the PDF file. }\end{array}$ \\
&
\end{tabular}

Thank you for your assistance. 